\title{
New Compact Wideband Microstrip Antenna for Wireless Applications
}

\author{
Shereen Abdalkadum Shandal', Yaqeen Sabah Mezaal'², Mohammed Aboud Kadim³, Mahmood Ferhan Mosleh ${ }^{1}$ \\ ${ }^{1}$ Electrical Engineering Technical College, Middle Technical University, Baghdad, Iraq \\ ${ }^{2}$ Medical Instrumentation Engineering Department, Al-Esraa University College, Baghdad, Iraq \\ ${ }^{3}$ Institute of Technology, Middle Technical University, Baghdad, Iraq \\ *corresponding author, E-mail: yakeen_sbah@yahoo.com
}

\begin{abstract}
In this paper, a miniature rectangular microstrip antenna over partial ground plane is presented by utilizing a space-filling property of fractal geometry in this design. It is simulated by High Frequency Software Simulator (HFSS) software, fabricated and tested by Vector Network Analyzer (VNA).Two types of slots are introduced in order to enhance antenna parameters such as bandwidth and return loss S1.1. This antenna is fabricated on FR4 substrate with a small size of $(18 \times 16 \times 1.5) \mathrm{mm}^{3}, 1.5 \mathrm{~mm}$ substrate thickness, 4.3 permittivity and 0.02 loss tangent. To feed this antenna, microstrip line feed is used. This antenna is implemented for wide bandwidth (4.8-11.6) GHz, and has three resonant frequencies at $5.5 \mathrm{GHz}, 8.3 \mathrm{GHz}$ and $10.7 \mathrm{GHz}$ with impedance bandwidth of $6.8 \mathrm{GHz}$. The gap value $g$ between partial ground plane and rectangular patch at top layer is optimized in order to achieve the optimal simulated return loss of (-46,32 and -14$) \mathrm{dB}$ at three resonant frequencies $(5.5,8.3$ and 10.7) $\mathrm{GHz}$ and optimal radiation efficiency of $93.42 \%$ with gain of $3.63 \mathrm{~dB}$. The simulated results have tolerable agreement with measured results. This antenna is suitable for wireless computer applications within $\mathrm{C}$ and $\mathrm{X}$ band communications.
\end{abstract}

\section{Introduction}

During last ten years, miniature size and inexpensive Micro Strip Antenna (MSA) has been evolved for different wireless communication applications such as handheld wireless devices and other computerized systems [1]. MSA is considered as a main reason for recent development in wireless communication technology [2]. For most antenna designers, MSA is an optimum option, because of its small size it can be easily mounted in communication devices [3]. It has an enticing attributes such as light weight, compactness, high efficiency [4], and compatibility with Integrated Circuit (IC) technology [4]. On the other hand, MSA has a narrow bandwidth [5]; there are several methods to overcome this problem, one of them by using fractal geometry [6]. Fractal geometry can be used to describe the occurrence of natural model that cannot be described by Euclidean geometry [7]. Fractal MSA is a design of MSA by using fractal technique that widely used for multiband and wideband applications in high data rate system [8]. Fractal has the main properties of space filling and self-similarity. Spaces filling can be used for MSA to increase the electrical length with longer surface current that makes the resonant frequency of MSA lower, while self-similarity property can help in generating multiple resonant modes [9]. The shapes of fractal are varying such as Koch, Sierpinski, Peano, Tree, and Snowflake fractal antennas [10]. It comes into two main variances; the first one is random fractal component that constituted randomly from a set of non-determined steps such as tree shaped fractal antenna, while deterministic (chaotic) fractal or geometric fractal that has several copied, scaled down and rotated part of original shape such as Koch curve fractal antenna[11].

In [12], the researcher proposed a miniaturized UltraWide Band (UWB) monopole microstrip antenna design by a combination of Giusepe peano and Sierpinski carpet fractals. This antenna is fabricated on FR4 substrate with dimensions of $(20 \times 25 \times 1.6) \mathrm{mm}^{3}$ and loss tangent of 0.02 . The first iteration of Giusepe peano is applied at the edges of square patch with employing a Sierpinski carpet fractal on its surface, while semi elliptical ground plane is used with microstrip line feed as a feeding method. The results indicate a wide bandwidth (2.4-16) GHz, good gain, high radiation efficiency and omnidirectional radiation pattern. In [13], a miniaturization of fractal antenna using novel Giusepe peano geometry for wireless applications was proposed. This antenna is fabricated on FR4 substrate with dimensions (38.9 $x 40 \times 1.6) \mathrm{mm}^{3}, 4.4$ permittivity and resonant frequency of 4GHz. The result shows that the first iteration has resonant frequencies of $3.61 \mathrm{GHz}, 6.20 \mathrm{GHz}$ and $8.43 \mathrm{GHz}$ frequency band. While the resonant frequencies of second iteration are $2.10 \mathrm{GHz}, 2.85 \mathrm{GHz}, 5.15 \mathrm{GHz}$ and $9.11 \mathrm{GHz}$. There is reducing in the resonant frequency of second iteration, which means the miniaturization is achieved without change the dimension of antenna. This type of antenna is used for different wireless applications such as WLAN, Bluetooth and $\mathrm{X}$ band. On the other hand, in [14] the researcher introduced a Koch boundary based on square patch microstrip antenna. The right angled triangular Koch curve is formed on the edges of square patch for achieving multiband antenna. FR4 substrate is used in this design with dimensions $(60 \times 55 \mathrm{x}$ 1.59) $\mathrm{mm}^{3}$ and permittivity of 4.4. The patch formation has been altered in several steps in order to realize antenna with multiband characteristic. This antenna resonates at several frequencies of $4.3 \mathrm{GHz}, 5.0 \mathrm{GHz}, 6.1 \mathrm{GHz}, 7.4 \mathrm{GHz}, 8.9 \mathrm{GHz}$ and $9.2 \mathrm{GHz}$, by adding a circle in the middle of patch. A circular polarization has been obtained near resonant frequencies with satisfactory results of gain, bandwidth and VSWR. In [15], a monopole antenna for frequency reconfigurable wide to narrow band has been designed using slotted ground plane and it consists of microstrip slot antenna 
and monopole antenna. The microstrip slot antenna exhibits three various frequency bands with resonant frequencies at $(3.02,3.89$ and 4.56$) \mathrm{GHz}$, while monopole antenna exhibits a wideband of (1.66-4.93)GHz. The copper strip and PIN diode has been used as switches and their effects are explained. There is a good agreement between simulation and measurement results in term of return loss and radiation patterns. On the other hand, a reconfigurable monopole antenna with a spiral-shape has been proposed in [16]. This antenna has been printed on substrate of FR4 with small size of $(32 \times 50.3 \times 1.8) \mathrm{mm}^{3}$. Switches have been used in this antenna design in order to generate a number of resonant frequencies for various switches states. This antenna can cover many frequency bands such as ISM band within (2.4$2.5) \mathrm{GHz}$ frequency range and Medical implant communication service band of (402-406)GHz. High agreement amid simulation and measurement results are existing which makes this antenna a worthy candidate for biomedical applications.

In this paper, miniature fractal MSA for wideband wireless applications has been tested. Four models are simulated by HFSS electromagnetic simulator. It is found that the best model that implies highest bandwidth consists of right-angled triangle boundary at left and right side of MSA with equilateral triangle boundary at top side of MSA and Giusepe Peano slot at the center of MSA. The best one has been fabricated, tested by Vector Network Analysis (VNA) and compared its simulation results with measured ones. All results are in good performance.

\section{Micro Strip Antenna (MSA)}

The traditional component of MSA is shown in Figure1. It consists of the following layers: The top layer is metallic layer that can be made from gold or copper. It consists of two parts; the first part is called patch or microstrip that may take any form and the second one is called microstrip line feed that used as transmission line. This layer is photoetched on dielectric substrate [14]. The medium layer is called a substrate. FR4 type substrate is commonly used, because it is widely available in the market. Also, each substrate has a thickness $h$ and permittivity $E_{r}$; both are determined according to the type of substrate used and the range of permittivity should be within $\left(1.4<E_{r}<12\right)$ range. MSA performance can be enhanced by controlling the substrate thickness $h$, therefore, it is considered as dominant factor for determining antenna electrical parameters. There is a relationship between thickness and permittivity; when thicker substrate is used with low value of permittivity, this makes antenna performance improved, but at the same time it has a disadvantage of increased dimension of antenna. Consequently, a compromise should be made between size and performance of MSA [17]. The bottom layer is called a ground plane layer. It may take any possible shape and it can be employed as either partial or full ground plane. It plays a crucial role to improve the bandwidth of MSA.

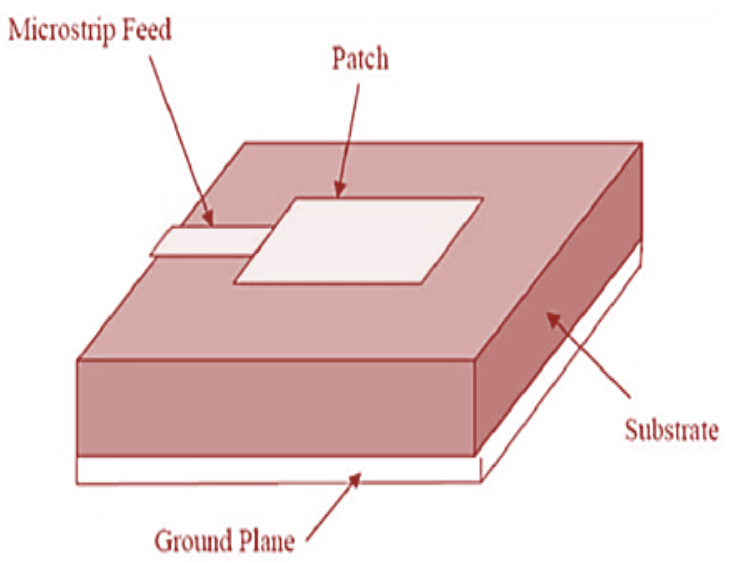

Figure 1: Components of MSA

\section{Proposed Antenna Model}

In this study, there are four different models are proposed for designing fractal MSA for wideband applications. The first model has rectangular MSA with Giusepe Peano boundary. The second model consists of rectangular MSA with Giusepe Peano slot at the centre to motivate a wideband characteristic. The third model has both Giusepe Peano boundary and Giusepe Peano slot at the center of rectangular MSA. The fourth model consists of right-angle triangle slot at the left and right side of MSA boundary with equilateral triangle shape slot at the top boundary of MSA and Giusepe Peano slot at the center to obtain antenna with higher impedance bandwidth than other models. All of four models are illustrated in Figure 2.

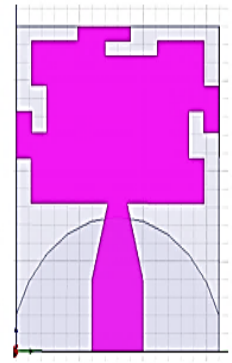

(a)

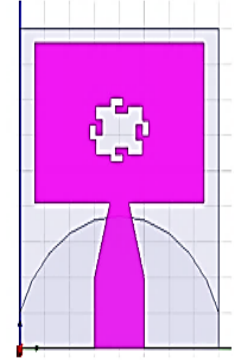

(b)

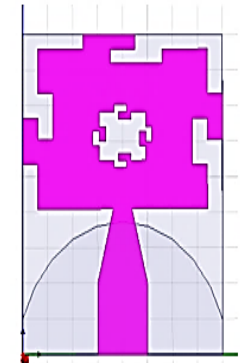

(c)

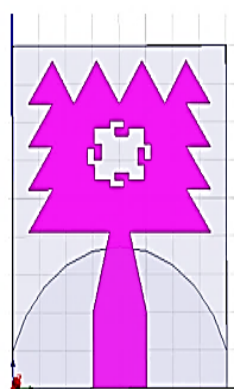

(d)

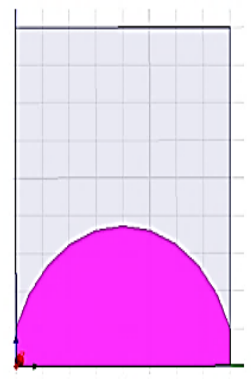

(e)
Figure 2: Different proposed models of Antenna (a) Model 1, (b) Model 2, (c) Model 3, (d) Model 4 (Top view) and (e) Model 4 (Bottom view) 
The length $\left(L_{p}\right)$ and width $\left(W_{p}\right)$ of rectangular MSA (model 4) is calculated by using equations (1) to (5) [13], and they are adjusted to be $9 \mathrm{~mm}$ and $13.6 \mathrm{~mm}$ respectively.

$$
\begin{aligned}
& W_{p}=\frac{c}{2 f_{r} \sqrt{\frac{E_{r}+1}{2}}} \ldots \ldots \ldots \ldots . \ldots(1) \\
& E_{\text {reff }}=\frac{E_{r}+1}{2}+\frac{E_{r}-1}{2}\left[1+12 \frac{h}{w}\right]^{\frac{1}{2}} \ldots \ldots \ldots(2) \\
& L_{e f f}=\frac{c}{2 f_{r} \sqrt{E_{\text {reff }}}} \ldots \ldots \ldots(3) \\
& \Delta L=0.412 h \frac{\left(E_{\text {reff }}+0.3\right)\left(\frac{w}{h}+0.246\right)}{\left(E_{\text {reff }}-0.258\right)\left(\frac{w}{h}+0.8\right)} \ldots \ldots .(4) \\
& L_{p}=L_{\text {eff }}+2 \Delta L \ldots \ldots \ldots(5)
\end{aligned}
$$

Where $c$ is velocity of light in free space, $h$ is substrate height, $E_{r}$ is relative permittivity of the substrate, $w_{p}$ is the width of patch, $L_{p}$ is the actual length of patch, $L_{e f f}$ is effective length, $E_{\text {reff }}$ is effective dielectric constant and $\Delta L$ is the extension dimension due to fringing field. The length of right-angle triangle slots at the left and right boundary of rectangular MSA is denoted by $L_{t}$, and at the same time it represents the height of equilateral triangle slot that can be calculated by:

$$
L_{t}=\frac{L_{p}}{4} \text {. }
$$

Where $L_{t}$ is equal to $2.25 \mathrm{~mm}$ after applying above equation. The area of right-angle triangle slots at the left and right boundary of rectangular MSA denoted by $A_{r}$ is calculated by equation (7):

$A_{r}=\frac{1}{2}\left(\mathrm{~L}_{t} * \frac{w_{p}}{8}\right)$

The value of $A r$ is equal to $1.91 \mathrm{~mm}^{2}$. Also, the area of equilateral triangle slots at the top side of rectangular MSA denoted by $A_{e}$ is calculated by equation (8) and it equals to $3.82 \mathrm{~mm}^{2}$ :

$A_{e}=\frac{1}{2}\left(\mathrm{~L}_{t} * \frac{w_{p}}{4}\right)$

The fractal Giusepe peano slot at the center of rectangular MSA is found by dividing the original rectangular MSA into nine small rectangles and cutting the center one only. Then, Giusepe Peano slots at all its sides up to first iteration are added in order to achieve an antenna with wideband characteristic. The initiator and generator of Giusepe Peano are shown in the figure below:

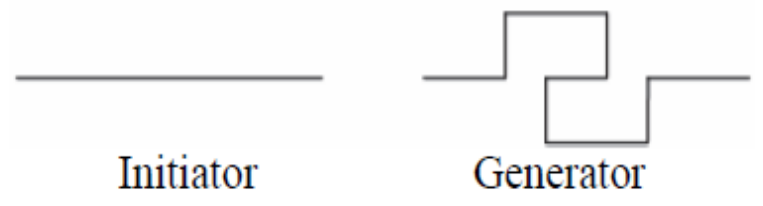

Figure 3: Giusepe Peano initiator and generator

The initiator length denoted by $X$ can be confined by any Giusepe Peano pre-fractal curve for $n$th iteration form $X_{n}$. It is calculated by [18]:

$X_{n}=2^{n} X_{n-1}$ for $\mathrm{n} \geq 1$

The model 4 is fabricated on FR4 substrate. It has a rectangular shape of $18 \mathrm{~mm}$ length and $16 \mathrm{~mm}$ width. The partial ground plane consists of rectangle $(3 \times 18) \mathrm{mm}^{2}$ and semi-elliptical shape, both are combined together and covering the feedline with a gap $g$ equals to $0.75 \mathrm{~mm}$ away from rectangular MSA. The feedline consists of two parts; the first one is rectangular shape with dimensions of $(4 \times 2) \mathrm{mm}^{2}$ and the second part is tapered rectangular shape with length of $4.23 \mathrm{~mm}$. Both of these two parts are combined together to form the feedline of rectangular MSA. The advantage of tapered feed line is to improve impedance matching. Also, the type of feeding used in this design is microstrip line feed. It is easy to fabricate with the simplest type of feeding methods. After optimization, the detailed dimensions of proposed antenna (model 4) are listed in Table 1. As well, the final geometrical view of proposed fractal MSA (model 4) is illustrated in Figure 4.

Table 1: The dimensions of Proposed Model 4

\begin{tabular}{|l|l|l|l|}
\hline Parameter & Value & Parameter & Value \\
\hline Permittivity $E_{r}$ & 4.3 & $\begin{array}{l}\text { Width of Rectangular MSA } \\
\text { (patch) } W_{P}\end{array}$ & $13.6 \mathrm{~mm}$ \\
\hline $\begin{array}{l}\text { Thickness of } \\
\text { substrate } h\end{array}$ & $1.5 \mathrm{~mm}$ & $\begin{array}{l}\text { Length of rectangular Giusepe } \\
\text { peano slot at top and bottom } \\
\text { sides }\end{array}$ & $1 \mathrm{~mm}$ \\
\hline Width of substrate $W_{s}$ & $18 \mathrm{~mm}$ & $\begin{array}{l}\text { width of rectangular Giusepe } \\
\text { peano slot at top and bottom } \\
\text { sides }\end{array}$ & $0.4 \mathrm{~mm}$ \\
\hline Length of substrate $L_{s}$ & $16 \mathrm{~mm}$ & $\begin{array}{l}\text { Length of rectangular Giusepe } \\
\text { peano slot at left and right } \\
\text { sides }\end{array}$ & $0.5 \mathrm{~mm}$ \\
\hline Width of ground $W_{g}$ & $18 \mathrm{~mm}$ & $\begin{array}{l}\text { width of rectangular Giusepe } \\
\text { peano slot at left and right } \\
\text { sides }\end{array}$ & $0.84 \mathrm{~mm}$ \\
\hline $\begin{array}{l}\text { Length of ground } L_{g} \\
\text { Senm }\end{array}$ & $\begin{array}{l}\text { Gap between ground and patch } \\
g\end{array}$ & $0.75 \mathrm{~mm}$ \\
\hline $\begin{array}{l}\text { Width of feed line } W_{f} \\
\text { Rectangular MSA } \\
\text { (patch) } L_{p}\end{array}$ & $2 \mathrm{~mm}$ & $\begin{array}{l}\text { Side length of right angle } \\
\text { triangle slot } S\end{array}$ & $2.88 \mathrm{~mm}$ \\
\hline $\begin{array}{l}\text { Length of right angle triangle } \\
\text { slot } L_{t}\end{array}$ & $3.4 \mathrm{~mm}$ \\
\hline
\end{tabular}




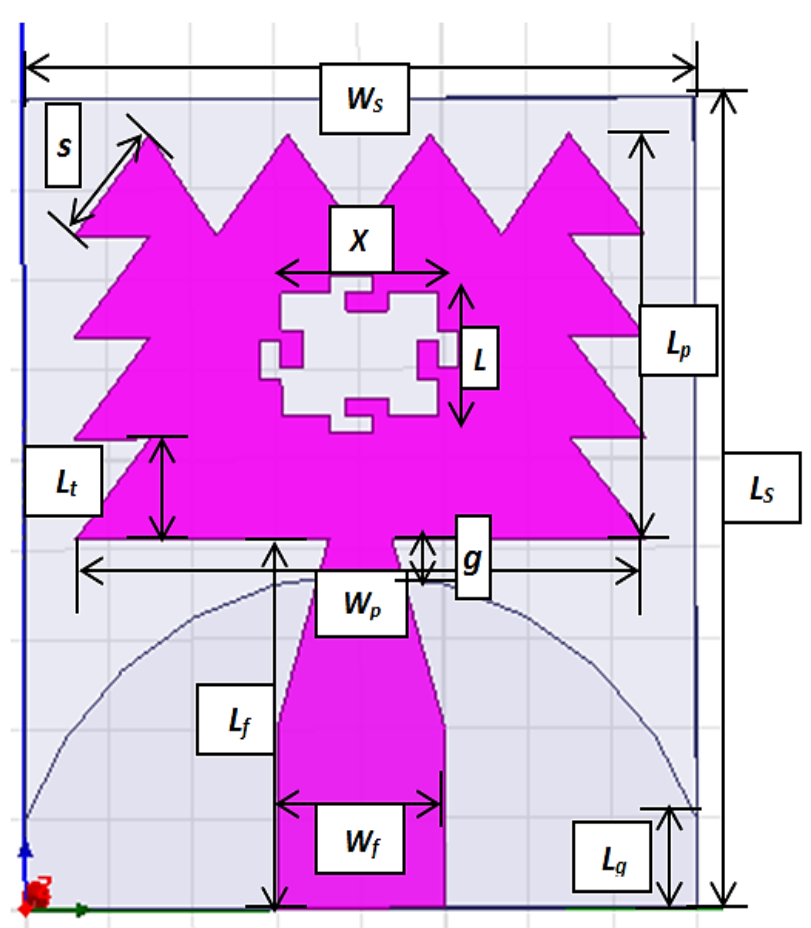

Figure 4: Geometrical view of model 4

\section{Results and Discussion}

Different models are investigated in order to obtain the best performance one. They have been designed and simulated by using Finite Element Method (FEM) based on HFSS simulator version 2014. A comparison between different models is listed in Table (2). From Table 2, it can be concluded that the model 4 (proposed model) is the optimum one. In accordance with it, the best return loss S1.1 are $(-46,-34$ and -14$) \mathrm{dB}$ at three resonance frequencies $(5.5$, 8.3 and 10.7) $\mathrm{GHz}$ with wide bandwidths among other models. So in that model, both of return loss S1.1 and bandwidth are enhanced that cannot be achieved by other models. While in model 1 that includes Giusepe Peano at boundary, the impedance bandwidth is $79 \%$ with adequate return loss values. The impedance bandwidth is increased remarkably at model 2 but the return loss S1.1 still somewhat keeps its previous values. In model 3, the impedance bandwidth is reduced with a small increase in return loss S1.1. So that, model 4 is the best choice. A comparison of return loss S1.1 at various values of frequency for different models is shown in Figure 5.

Table 2: Comparison of Proposed Model Based on Various Models.

\begin{tabular}{|c|c|c|c|c|c|}
\hline Model & S1.1 (dB) & $\begin{array}{c}\text { Resonance } \\
\text { frequency } \\
\text { (GHz) }\end{array}$ & $\begin{array}{c}\text { Impedance } \\
\text { bandwidth }\end{array}$ & $\begin{array}{c}\text { Radiation } \\
\text { efficiency }\end{array}$ & $\begin{array}{c}\text { Gain } \\
\text { (dB) }\end{array}$ \\
\hline Model 1 & $-27.4,-16$ & $5.3,8.3$ & $79 \%$ & $94.59 \%$ & 3.50 \\
\hline Model 2 & $\begin{array}{c}-28.4,- \\
16.2,-14.2\end{array}$ & $5.4,8.8,10.8$ & $85 \%$ & $94.33 \%$ & 3.68 \\
\hline Model 3 & $-31.2,-18.2$ & $5.3,8.3$ & $75 \%$ & $94.43 \%$ & 3.57 \\
\hline $\begin{array}{c}\text { Model 4 } \\
\text { (Proposed) }\end{array}$ & $\begin{array}{c}-46,-32,- \\
14\end{array}$ & $5.5,8.3,10.7$ & $84 \%$ & $93.42 \%$ & 3.63 \\
\hline
\end{tabular}

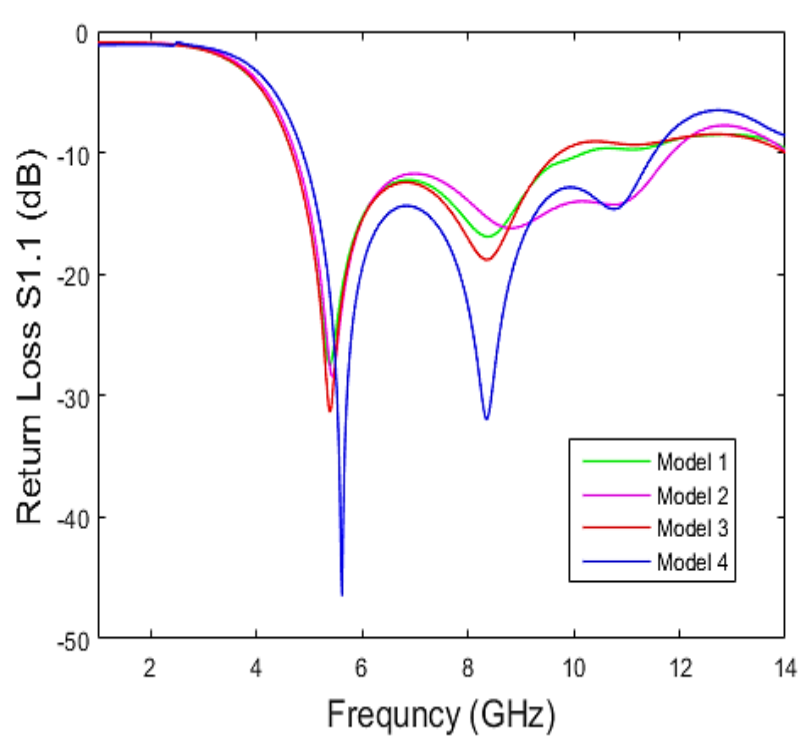

Figure 5: Simulated return loss S1.1 for various iterations number

Also, the proposed model 4 is simulated by changing the value of gap $\mathrm{g}$ to enhance the antenna parameters such as (bandwidth, return loss S1.1 and gain). It is clear that the gap value $g$ is an adjusting factor to determine the optimal bandwidth of antenna. As shown in Table 3, it indicates the best value for $g$ is $0.75 \mathrm{~mm}$. Because of that value, the best matching can be obtained between input impedance Zin and characteristic impedance of feed line that equals to $50 \Omega$. A comparison of return loss S1.1 at different frequencies for different gap values is displayed in Figure 6.

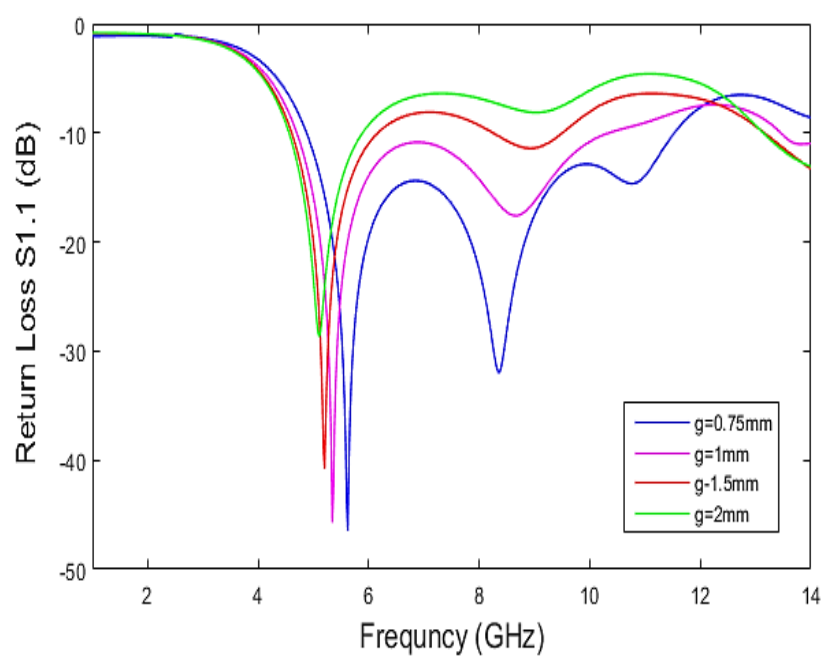

Figure 6: Simulated return loss S1.1 for different values of gap $g$ 
The Voltage Standing Wave Ratio (VSWR) of proposed model 4 is illustrated in Figure 7. It has a proper value at three resonance frequencies $(5.5,8.3$ and 10.7$) \mathrm{GHz}$ that should be below or equal to 2 . When the value of VSWR is higher than 2 , it means there is a high mismatching between input impedance of antenna Zin and characteristic impedance of feedline. This makes the antenna will not work effectively. The input impedance Zin of model 4 reaches somewhat to characteristic impedance of feedline $50 \Omega$ at bandwidth range of (4.5-12) GHz.

Table 3: Comparison of Proposed Model Based on $g$.

\begin{tabular}{|c|c|c|c|c|c|}
\hline$g(m m)$ & S1.1(dB) & $\begin{array}{c}\text { Resonance } \\
\text { frequency }(\mathrm{GHz})\end{array}$ & \begin{tabular}{|l|} 
Impedance \\
bandwidth
\end{tabular} & $\begin{array}{l}\text { Radiation } \\
\text { efficiency }\end{array}$ & $\begin{array}{l}\text { Gain } \\
\text { (dB) }\end{array}$ \\
\hline \begin{tabular}{|c|}
0.75 \\
(proposed)
\end{tabular} & $\begin{array}{c}-46,-32 \\
,-14\end{array}$ & $5.5,8.3,10.7$ & $84 \%$ & $93.42 \%$ & 3.63 \\
\hline 1 & $\begin{array}{l}-45.5 \\
-17.5\end{array}$ & $5.3,8.6$ & $80.5 \%$ & $94.38 \%$ & 3.48 \\
\hline 1.5 & $\begin{array}{l}-40.5 \\
-11.4\end{array}$ & $5.1,8.9$ & $31 \%, 12 \%$ & $93.85 \%$ & 3.52 \\
\hline 2 & -28.5 & 5 & $26 \%$ & $93.76 \%$ & 3.43 \\
\hline
\end{tabular}

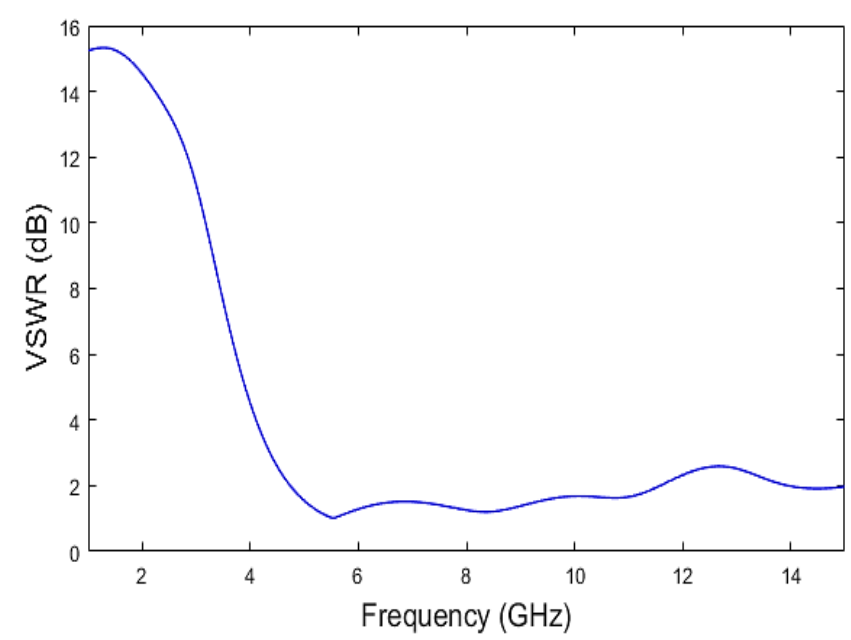

Figure 7: Simulated VSWR of model 4

After simulation of proposed model and getting the finest parameters values for designing fractal rectangular MSA that mentioned previously in Table (1). This proposed model is fabricated on FR4 substrate of $(18 \times 16 \times 1.5) \mathrm{mm}^{3}$ dimensions and tested by (VNA). The fabricated model is shown in Figure 8. A comparison between measured return loss of fabricated model with simulated return loss is presented in Figure 9.

The return loss S1.1 curve in Figure 9 indicates an acceptable discrepancy between simulated and measured results. The differences between them occur due to many reasons such as the effect of soldering and fabrication tolerance. Also, SMA connectors cannot implemented in HFSS software, but instead it uses microstrip line feed so that the difference between them may cause this simple disparity.

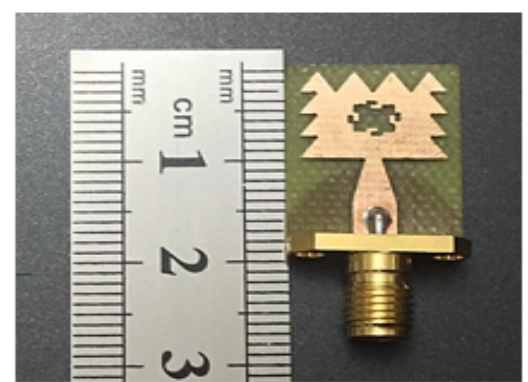

(a)

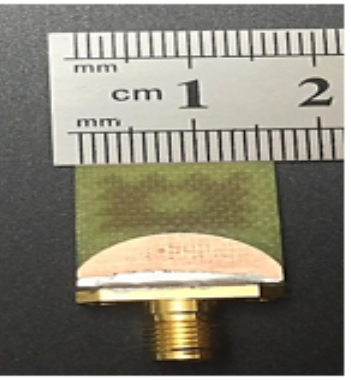

(b)

Figure 8: Fabricated prototype of proposed model (a) Top View (b) Bottom View

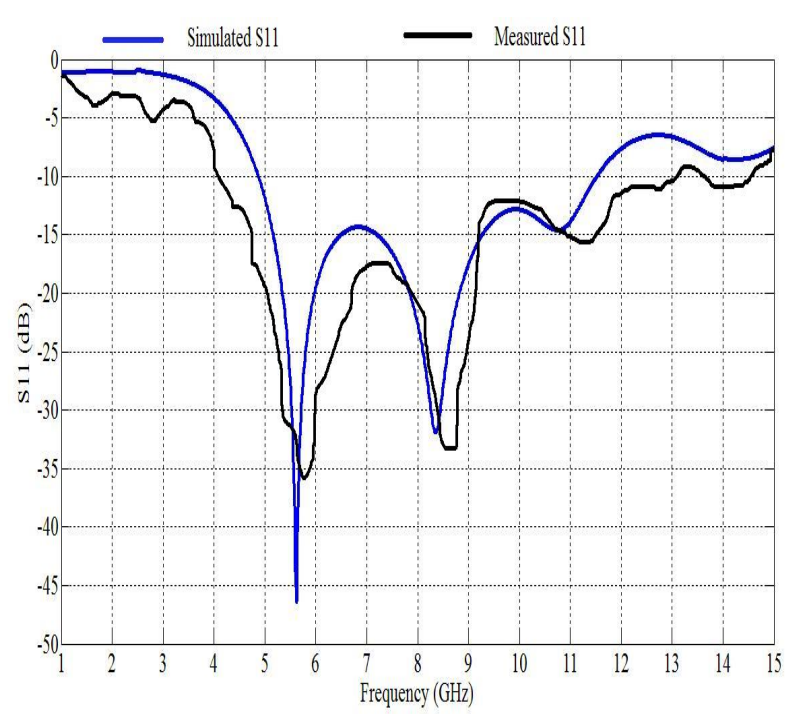

Figure 9: Simulated return loss as compared with the measurement

The 2D Radiation patterns of proposed model for three resonant frequencies are depicted in Figure 10, that point to far field radiation pattern at three resonant frequencies $(5.5$, 8.3 and 10.7) GHz. By taking two values of phi at 0 degree that represents $\mathrm{XZ}$ plane and at 90 degree that represents $\mathrm{YZ}$ plane, It is clear that the proposed model has a bi-directional radiation patterns and there is appearance of side lobe at higher resonant frequency of $10.7 \mathrm{GHz}$ 


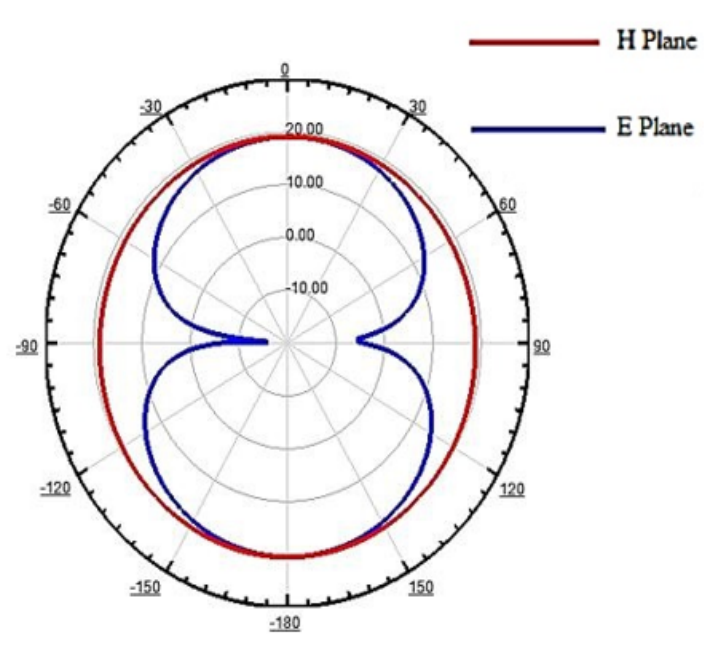

(a)

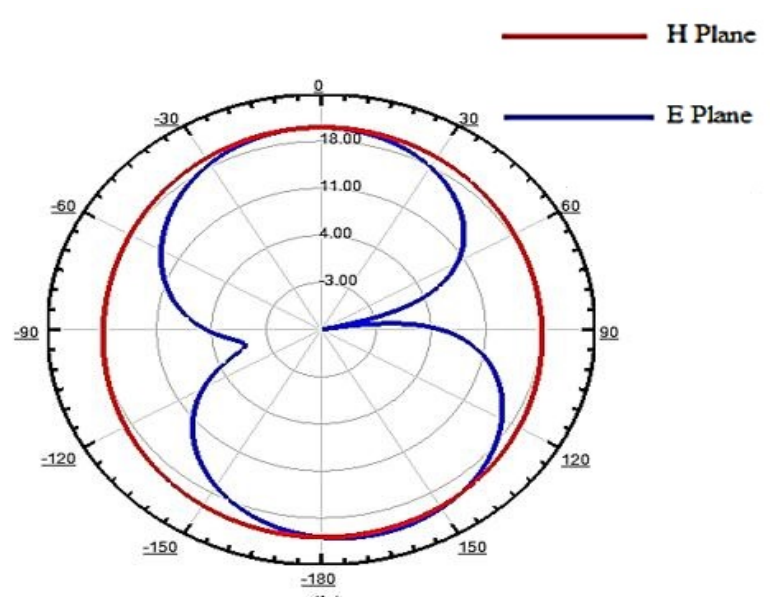

(b)

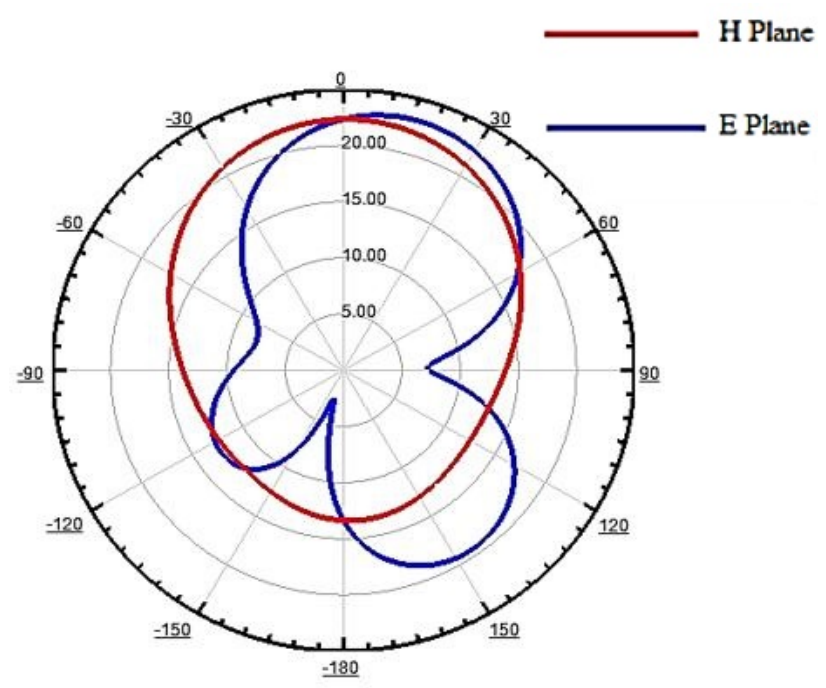

(c)

Figure 10: Simulated 2D Radiation Patteren at resonant frequncies of (a) $5.5 \mathrm{GHz}$,(b) $8.3 \mathrm{GHz}$, and (c) $10.7 \mathrm{GHz}$
The gain of proposed model is presented in Figure 11, which points to gain for a frequency band (4-15) GHz. It is clear that the gain reaches the peak value at $11 \mathrm{GHz}$ that equals to $5.7 \mathrm{dBi}$. Subsequently, it starts to decrease progressively.

In Figure 12, the 3D polar plot gain and directivity is illustrated. The values of gain at various resonant frequencies $(5.5,8.3$, and 10.7) $\mathrm{GHz}$ is $(2,3.5$ and 5.1) $\mathrm{dB}$ respectively. After acquiring the gain and directivity of proposed model, it is easy to find the radiation efficiency that can be calculated by [19]:

Radiation efficiency $=\frac{\text { gain }}{\text { directivity }} * 100 \%$

Accordingly, the amount of radiation efficiency is equal to $95 \%$ at $5.5 \mathrm{GHz}, 93 \%$ at $8.3 \mathrm{GHz}$ and $88 \%$ at $10.7 \mathrm{GHz}$ as illustrated in Figure 13.

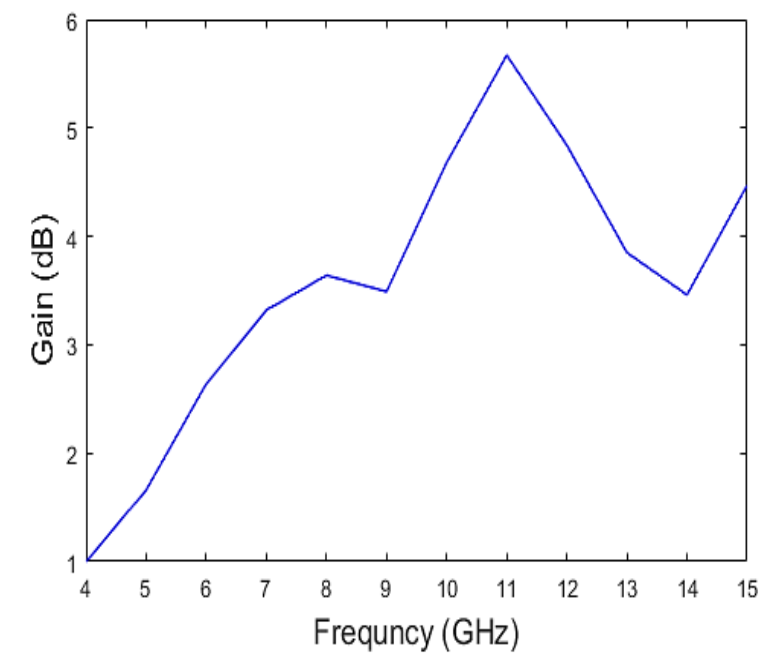

Figure 11: Simulated Gain versus frequency

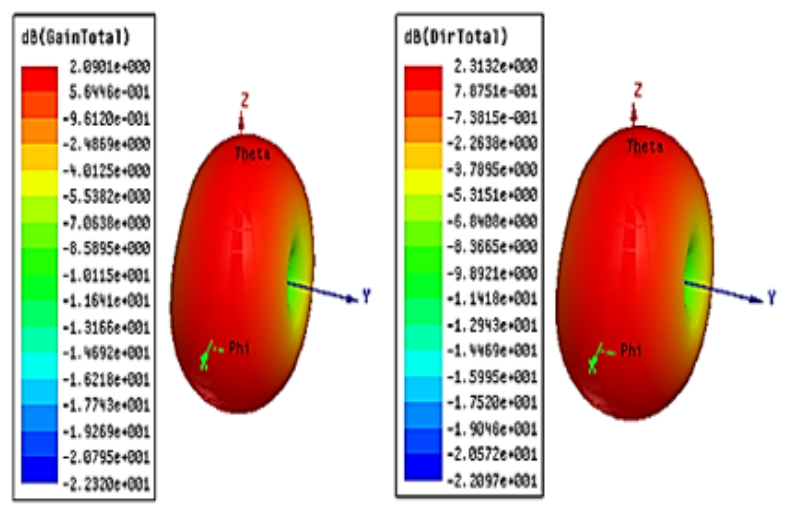

$\begin{array}{ll}\text { (a) Gain at } 5.5 \mathrm{GHz} & \text { (b)Directivityat } 5.5 \mathrm{GHz}\end{array}$ 


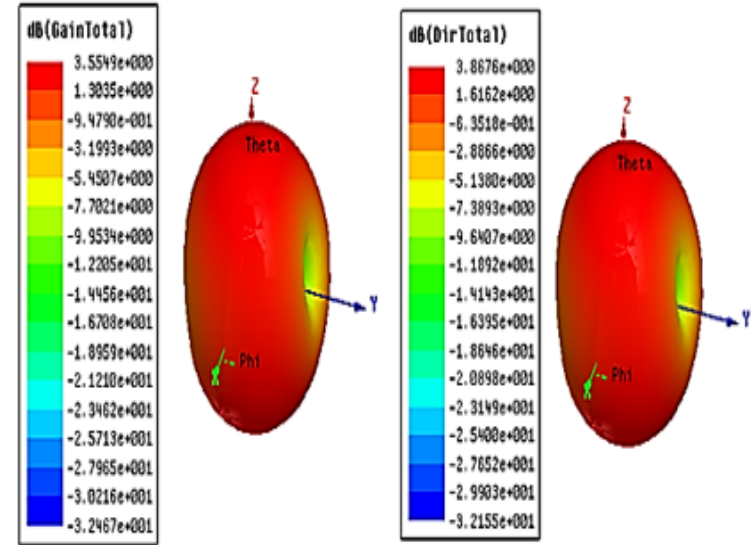

(c) Gain at $8.3 \mathrm{GHz}$

(d) Directivity at $8.3 \mathrm{GHz}$
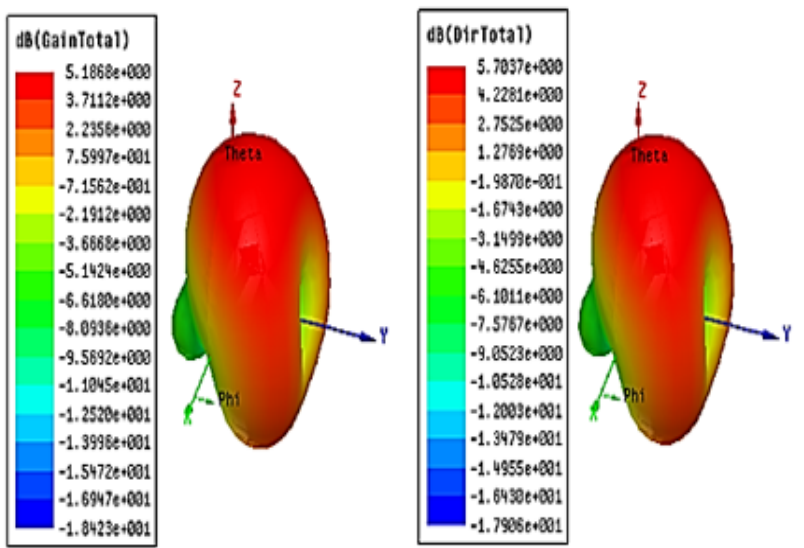

(e) Gain at $10.7 \mathrm{GHz}$

(f) Directivity at $10.7 \mathrm{GHz}$

Figure 12: 3D Polar Plot Gain and directivity at three resonance Frequncies $(5.5,8.3$ and 10.7$) \mathrm{GHz}$

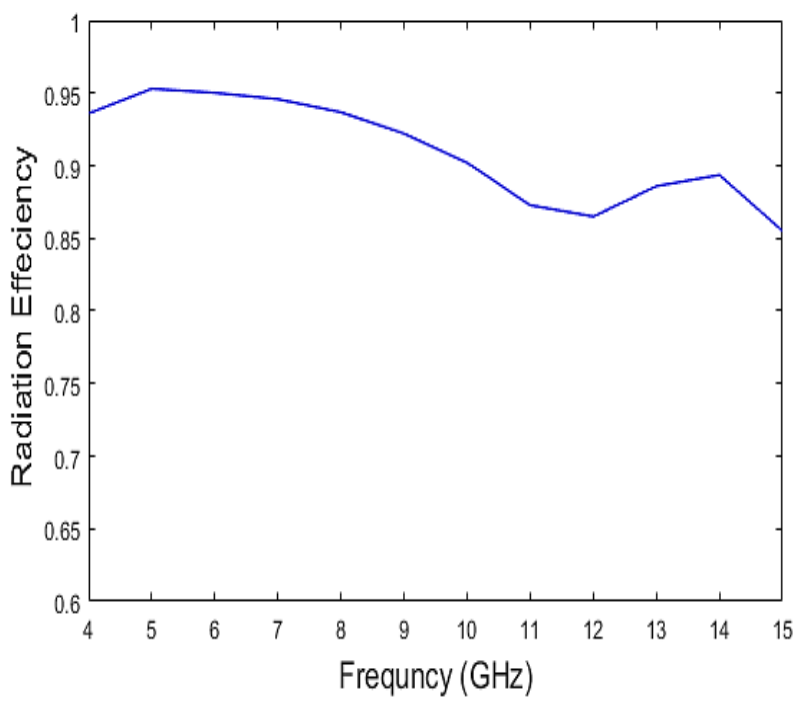

Figure 13: Radiation efficiency of proposed model

\section{Conclusions}

A new small size Fractal rectangular MSA has been proposed to operate at a bandwidth of (4.8-11.6) GHz. A comparison is made between four different proposed models that have been simulated by HFSS software. The best performance one was model 4 ; it has been optimized to get the optimum geomatric structure, fabricated and tested by VNA. Two types of slot are presented in this design in order to achieve both of wide bandwidth and improved return loss S1.1. These slots are etched on the top layer of MSA. It can be concluded that the first type of slot that has a shape of right angle triangle at left and right side of rectanglular MSA with equallitral triangle at the top, has advantage of reducing the return loss S1.1value to $-46 \mathrm{~dB}$. Also, the second type of slot that has a shape of Giusepe Peano curve up to first iteration has advantage of increased bandwidth to $6.8 \mathrm{GHz}$ and miniature antenna size. The gap $g$ value is optimized, and the best value is $0.75 \mathrm{~mm}$ to acquire the widest bandwidth. The proposed model has a compact size of $(18 \times 16 \times 1.5) \mathrm{mm}^{3}$. The simulated return loss S1.1 has been valued to $(-46,-32$ and -14$) \mathrm{dB}$ and the fractional impedance bandwidth is $84 \%$. The simulated results have tolerable agreement with measured results. The proposed model has a stable radiation patterns that make it suitable for wibeband applications within $\mathrm{C}$ and $\mathrm{X}$ bands. It can be integrated within many wireless computer networks as well as Intrnet of Things (IOT) utilities.

\section{Acknowledgments}

We would like to thank the staff of Electronic Manufacturing Unit/Micro strip section in the technology and science ministry for their support to fabricate the proposed model with the required measurements.

\section{References}

[1] H. Rajabloo, V. A. Kooshki and H. Oraizi, "Compact microstrip fractal Koch slot antenna with ELC coupling load for triple band application," AEU - International Journal of Electronics and Communications, Vol. 73, pp. 144-149, 2017.

[2] S. Dwivedi, "Analysis and Simulation of Sierpinski Carpet Type Fractal Multiband Antenna for Wide Band Applications," International Journal of Electronics Communication and Computer Engineering, Vol. 6, Issue 4, pp. 460-462, 2014.

[3] P. Mishra, S. S. Pattnaik and B. S. Dhaliwal, "Square-Shaped Fractal Antenna under Metamaterial Loaded Condition for Bandwidth Enhancement," progress In Electromagnetics Research C, Vol. 78, pp. 183-192, 2017.

[4] B. L. Shahu, S. Pal and N. Chattoraj, "A Compact Super Wideband Monopole Antenna Design using Fractal Geometries," Microwave Review, Vol. 20, No.2, pp 20-24, December, 2014.

[5] Z. Yu, J. Yu, X. Ran and C. Zhu, "A Novel Ancient Coin-Like Fractal Multiband Antenna for Wireless 
Applications," International Journal of Antennas and Propagation, 2017.

Article ID 6459286, pp. 10 pages, 18 April 2017, https://doi.org/10.1155/2017/6459286.

[6] M. GUPTA and V. MATHUR, "Koch fractal-based hexagonal patch antenna for circular polarization," Turkish Journal of Electrical Engineering \& Computer Sciences, pp. 4474-4485, 2017. doi:10.3906/elk-1702-295

[7] P. Dalsania, B. Shah and V. V. Dwivedi, "Analysis of Multiband Behaviour on Square Patch Fractal Antenna," International Conference on Communication Systems and Network Technologies, pp. 76-78, 2012.

[8] J. S. Sivia and S. S. Bhatia, "Design of Fractal Based Microstrip Rectangular Patch Antenna for Multiband Applications," International Advance Computing Conference (IACC), pp. 712-715, 2015.

[9] F. Wang, F. Bin, Q. Sun, J. Fan and H. Ye, "A Compact UHF Antenna Based on Complementary Fractal Technique," IEEE Access, Vol. 5, pp. 21118-21125, September 26, 2017.

[10] P. Kaur, A. De and S. K. Aggarwal, "Design of A Novel Reconfigurable Fractal Antenna for MultiBand Application," International Journal of Advanced Science and Technology, Vol.62, pp.103-112, 2014. http://dx.doi.org/10.14257/ijast.2014.62.08

[11] M. Kumar, "Design and analysis of Minkoski fractal antenna using microstrip feed," International Journal of Application or Innovation in Engineering \& Management (IJAIEM), Vol. 3, Issue 1, ISSN 2319 - 4847 , January 2014

[12] H. Oraizi and S. Hedayati, "Miniaturized UWB monopole microstrip antenna design by the Combination of Giusepe Peano and Sierpinski carpet fractals," IEEE ANTENNAS AND WIRELESS PROPAGATION LETTERS, Vol. 10, pp. 67-70, 2011

[13] N. Sharmal, G. P. Singh and V. Sharma, "Miniaturization of fractal antenna using novel Giuseppe Peano geometry for wireless applications," 1st IEEE International Conference on Power Electronics. Intelligent Control and Energy Systems, 2016.

[14] M. Gupta and V. Mathur, "Koch boundary on the square patch microstrip antenna for ultra-wideband applications," Alexandria Engineering Journal (2017), http://dx.doi.org/10.1016/j.aej.2017.06.005

[15] H.A. Majid, M.K.A. Rahim, M.R. Hamid, M.F. Ismail and F. Malek, "Frequency reconfigurable wide to narrow band monopole with slotted ground plane antenna," Journal of Electromagnetic Waves and Applications, Vol. 26, pp. 1460-1469, 2012.

[16] M. Salim and A. Pourziad, "A Novel Reconfigurable Spiral-Shaped Monopole Antenna for Biomedical Applications," Progress In Electromagnetics Research Letters, Vol. 57, pp. 7984,2015 .
[17] C. A. Balanis, Antenna Theory Analysis And Design, John Wiley \& Sons, Inc., Fourth edition 2016.

[18] S. F. Abdulkarim, A. J. Salim, J. K. Ali, A. I. Hammoadi, M. T. Yassen and M. R. Hassan, "A compact Peano-type fractal based printed slot antenna for dual band wireless applications," IEEE international RF and Microwave Conference (RFM), Penang, pp. 329-332, 2013.

[19] S. O. Zakariyya, "Modeling of Miniaturized, Multiband and Ultra-Wideband Fractal antenna," M.Sc. Thesis, Institute of Graduate studies and research, Eastern Mediterranean University, Gazimagusa, North Cyprus, 2015. 